The Journal of Clinical Pathology

\section{The Journal of Clinical Pathology}

\section{R Chetty}

\section{Quo vadis?}

"Idealism is what precedes experience; cynicism is what follows." David T Wolf (Born 1943).

A lthough the new editorial team has been operating for the past 10 months, it is only now that they have really bedded down. I have deferred writing an editorial until a few key and pertinent issues have been addressed. I am most grateful to the outgoing team of Helen Holzel and Paul van Diest for their tremendous hard work and enthusiasm. This was and continues to be supplemented by an incredibly supportive BMJ publishing group editorial staff.

In many ways, the Journal of Clinical Pathology is at a crossroads and taking the right path is not governed by an easy to follow set of parameters. The journal has a rich history of 50 plus years and set out originally to provide pathologists with an all embracing publication, probably reflective of what pathologists did then. The burning question is whether the journal still caters for the needs of the current day pathologist. There is no doubt that there has been a remarkable transformation in the way pathology is practised, especially in the past 20 years. Changes have been rapid, imperceptible, and have become entrenched. How does the journal respond?

$J C P$ has occupied a unique place on the library shelf in being a pan-pathology journal in a climate of ever increasing subspecialisation. In the face of stiff competition from specialty based publications, can a broad spectrum journal survive? How does JCP retain its unique general appeal without sacrificing quality and trying to be all things to everyone? This is in essence the challenge that confronts the journal. Several changes are envisaged and indeed have been dictated by the readership in a recent survey.

The online electronic submission and review system has been a major boost to the expeditious handling of manuscripts and has removed the vagaries of an erratic mailing system. This has been met with approval from all parts of the world, with the vast majority of people very satisfied. The electronic revolution will reach even the most resistant! Authors are particularly pleased with the greatly improved turnaround times.

In January 2004, the Molecular Pathology edition was incorporated into the main issue. With this move, a name change of the journal was contemplated, but JCP remains the trademark name of the consolidated journal, with the added line of "incorporating Molecular Pathology". Without wishing to dwell on the polemics of a name change, the consensus is that molecular pathology transcends artificial subdivision and is equally applicable to all branches of pathology. The number of papers containing molecular techniques and methodology is increasing and is symptomatic of the way modern pathology is practised.

$J C P$ also has a role in education, both of pathologists and trainees, and its content will be geared towards fulfilling this important function. The "My approach" series, the first of which is published in this issue, ${ }^{1}$ hopes to provide the reader with an opportunity to see how a recognised authority in a particular field thinks and handles difficult issues.

Providing a balanced fare, which caters for all pathologists is an unenviable task, as I have discovered. There is a perception (and I confess that it is real in many instances) that $J C P$ is heavily slanted towards histopathology. This may well be a reflection of the fact that there are more histopathologists (certainly submitting manuscripts) around or that the other branches tend to submit to their specialty based journals. I want to stress that the content of the journal is a reflection of the submissions. It is a goal of this editorial team to encourage submissions from all branches in pursuit of delivering a balanced journal.

Making the journal a truly global player, being sensitive to the needs of the readership, and pursuance of quality publications are the basic tenets that will allow JCP to fulfil its niche on the shelf of pathology departments and libraries around the world.

J Clin Pathol 2004;57:238.

doi: 10.1136/jcp.2003.013987

Correspondence to: Professor R Chetty, Department of Pathology, University Health Network, Princess Margaret Hospital, 610 University Avenue, 4th Floor, Suite 302, Toronto, Ontario M5G 2M9, Canada; Runjan.Chetty@uhn.on.ca

\section{REFERENCE}

1 Asa SL. My approach to oncocytic tumours of the thyroid. J Clin Pathol 2004;57:225-32. 